This item was submitted to Loughborough's Institutional Repository (https://dspace.lboro.ac.uk/) by the author and is made available under the following Creative Commons Licence conditions.

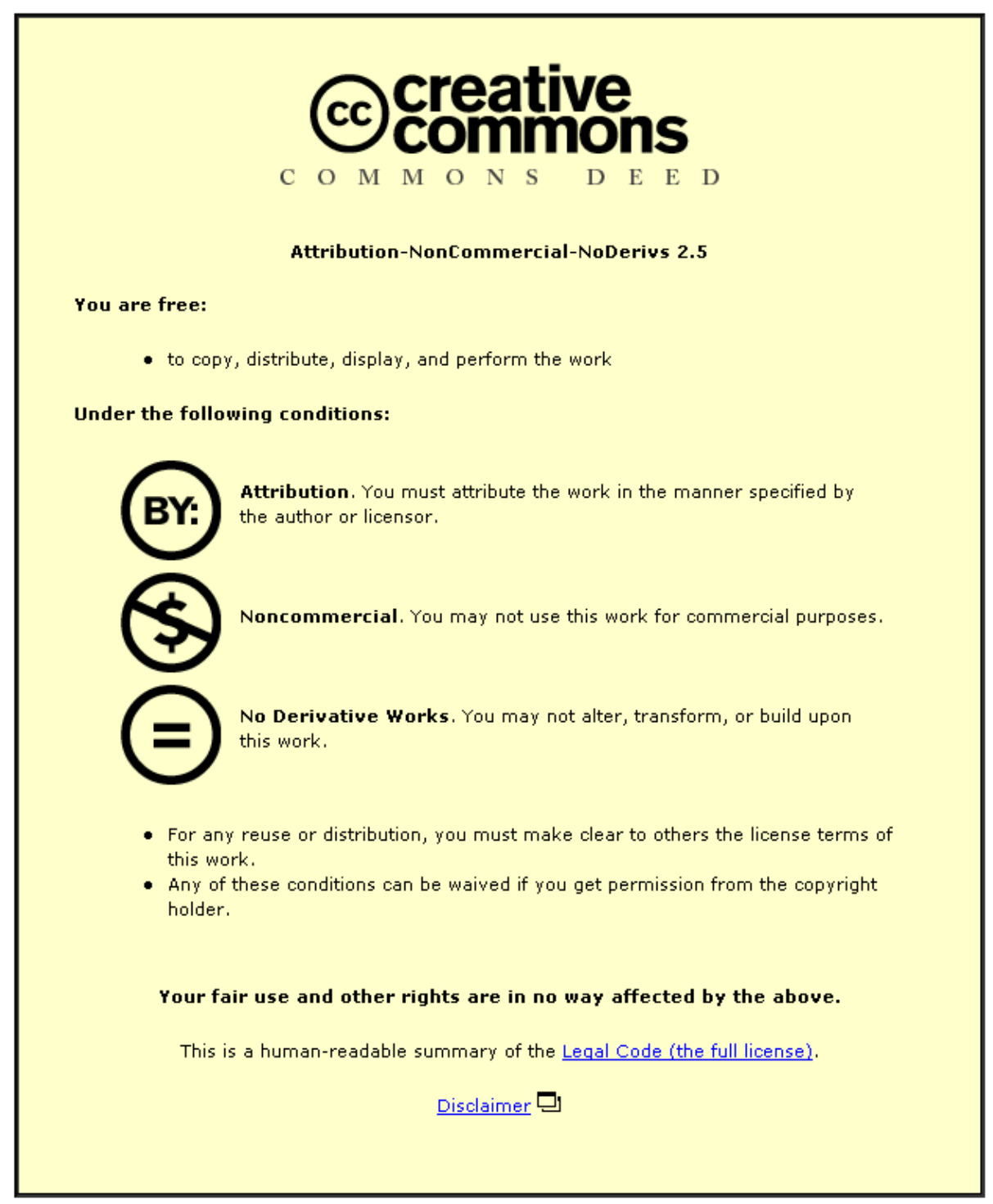

For the full text of this licence, please go to: http://creativecommons.org/licenses/by-nc-nd/2.5/ 


\title{
Requirements for a Registry of Electronic Licences
}

\author{
Mark Bide, Rajveen Dhiensa, Hugh Look, Charles Oppenheim \& Steve Probets
}

The Authors:

Charles Oppenheim is a professor, Steve Probets is a lecturer and Rajveen Dhiensa is a researcher; all in the Department of Information Science at Loughborough

University. Steve Probets is the corresponding author.

Mark Bide and Hugh Look are senior consultants with Rightscom Limited, a specialist media consultancy.

\section{Full Author Biogs}

\section{Professor Charles Oppenheim BSc PhD DSc DipInfSc CertEd HonFCLIP FCLIP FRSA AUMIST}

Charles Oppenheim has been Professor of Information Science at Loughborough University since 1998. He became Head of the Department of Information Science in 2006. In his past life, he has held a variety of posts in academia and the electronic publishing industry, working for International Thomson, Pergamon and Reuters at various times.

Charles is an Honorary Fellow of the Chartered Institute of Library and Information Professionals. He is one of only three people in the world to have been awarded a higher doctorate in Information Science. He is a member of the Legal Advisory Board of the European Commission. He is a regular contributor to conferences and to the professional and scholarly literature, and is on the editorial board of several professional and learned journals, and of Annual Review of Information Science and Technology.

\section{Mark Bide}

Mark Bide joined Rightscom in March 2001, following nearly 10 years running his own consultancy. He has over 35 years experience of the publishing industry, having been a Director of the European subsidiaries of both CBS Publishing and John Wiley \& Sons. Subsequently, he developed one of the most highly respected independent publishing consultancies in the UK, with particular expertise in the impact of network technology on the information value chain. Since the early 1990s, he has been deeply involved in metadata and identification initiatives, including the $<$ indecs $>$ project. At Rightscom, Mark has undertaken projects on behalf of many clients including the European Commission, the British Library, the Publishers Association, EDItEUR, UKOLN, the JISC, the Publishers Licensing Society, the Copyright Licensing Agency, the International DOI Foundation, the Recording Industry Association of America and the World Association of Newspapers. He has long been an advocate of the requirement for machine-interpretable policy expression, and has been involved in the formulation of ONIX for Licensing Terms from its inception. He is currently particularly engaged in the ACAP project (see www.the-acap.com), of which he is the Project Director.

\section{Dr Steve Probets}

Steve Probets has been a lecturer in Information Science at Loughborough University since 2001. Prior to that he worked in the Electronic Publishing Research Group at 
Nottingham University developing PDF and XML-based publishing solutions for a number of JISC funded eLib projects (Open Journal Framework, Espere), scholarly publishers (Wiley, Chapman \& Hall/Thomson, Thomas Telford), and software developers (Adobe, ComputerStream). Since moving to Loughborough he has been a co-investigator on the JISC-funded RoMEO project (Rights Metadata for Open Access). A subsequent project, which evolved from RoMEO, involved refinement of the SHERPA/RoMEO database of journal publishers copyright transfer agreements. Steve investigated appropriate technical architectures as part of a JISC funded project considering a 'Delivery, Management and Access Model for Eprints and Open Access Journals within Further and Higher Education'. Recently has been co-investigator on the JISC funded RELI (Registry of Electronic Licences) project which commenced in April 2007.

\section{Hugh Look}

Hugh Look joined Rightscom in January 2004, after many years working as an independent consultant. On joining Rightscom, Hugh mainly worked on Publishing Watch, a major year-long study of competitiveness of the European publishing industries. The study was for the European Commission's Directorate-General for Enterprise, and its objective was to identify the main issues affecting the publishing industries' competitiveness and ability to modernise and innovate at a time of enormous change in the technical, commercial and social environments within which publishing operates. He has also either led or been closely involved in many other Rightscom projects, ranging from new business models for electronic publishing to strategic planning for a new digital music service. Hugh has led two projects carried out for the Research Information Network: one being an analysis of research funders' policy and practice for the management of research outputs; and the other a major survey of how academic researchers use resource discovery services. He has either led or been a major contributor to reports for JISC on business models for e-journals and on differences between disciplines in the creation and use of information, as well as an analysis of the impact of digital copying licences in FE colleges for the CLA. He was the project manager for the Time project, which developed a testbed for interoperable ebook metadata. Hugh has carried out strategic reviews of projects and operations for content and media industry clients in a wide variety of settings, ranging from learned societies to government departments and large corporates. As both a consultant and a senior manager he has been involved in the management of major changes in organisations. Before becoming a consultant, Hugh held senior management positions at Longman Cartermill (Longman Group’s electronic publishing subsidiary) and Learned Information.

\section{Rajveen Dhiensa}

Rajveen Dhiensa graduated with a distinction in MSc Information and Knowledge Management. from the Department of Information Science at Loughborough University in 2006. Since then she has been a research associate on two research projects. The first of these was "User Needs and Potential Users of Public Repositories: An Integrated Analysis” which focused on evaluating five public repositories through qualitative and quantitative methods. The other project was the Reli project which is discussed in this paper. Raj was integral in running the focus groups and extracting the key points from the recordings. Alongside working on the RELI project, Raj was commissioned to carry out a survey of User and Deposit Licences for institutional repository managers. 


\title{
Requirements for a Registry of Electronic Licences
}

\author{
Mark Bide, Rajveen Dhiensa, Hugh Look, Charles Oppenheim \& Steve Probets
}

\section{Keywords}

Electronic publishing, licensing issues, ONIX for licensing terms, ONIX for publications licences, Registry of electronic licences.

\begin{abstract}
Purpose: The paper presents a brief history of electronic licensing initiatives before considering current practices for managing licences to electronic resources. The intention was to obtain a detailed understanding of the requirements needed for a registry of electronic licences that would enable usage terms and conditions to be presented to end-users at point of use.

Approach: Two extensive focus groups were held, each comprising representatives from the main stakeholder groups. These structured events considered existing and ongoing issues and approaches towards licence management and investigated a range of 'use-cases' where potential usages for a licence registry were outlined and discussed.

Findings: The results form part of a requirements gathering and analysis process which will inform the development of a registry of electronic licences. This work forms part of the JISC-funded Registry of Electronic Licences (RELI) project.. The paper finds that there are many complexities when dealing with electronic licences such as licence specificity, licence interpretation, definitions of authorised users and dissemination of usage terms and conditions.

Implications: These issues and others are considered and the impact on a subsequent registry of electronic licences is discussed. It is clear from the findings that there is a real and immediate need for a licence registry.

Originality: The paper provides a rich picture of the concerns and practices adopted both when managing licences and ensuring conformance with licences to electronic resources. The findings have enabled the scope of a licence registry to be determined. The registry is currently under development.
\end{abstract}

\section{Introduction}

Most of the electronic versions of journals, electronic books and databases of digital images and datasets are licensed from copyright holders rather than purchased outright. As more and more digital resources are licensed by libraries, the difficulties involved in managing the licences increase. In addition, there are difficulties in ensuring that users of the digital resources adhere to the terms and conditions specified in the licence agreements. These difficulties are in part due to the many different types of resource that are managed by libraries, ranging from e-journals, ebooks, videos, images and datasets to e-learning materials; and in part due to the wide range of usage terms specified in the various licence agreements. Some licences govern agreements between publishers/aggregators and libraries and outline the terms of use for the resource, whilst other licences may be concerned with allowable uses for resources mounted in University-based institutional or learning repositories. 
Users of digital resources, and the institutions within which those users work or study, do not have the knowledge that they require to enable them to comply with the licensing terms established by those who hold the rights to the resources. As the medium for the distribution of resources (which may be for teaching, research or administration purposes) moves increasingly from physical copies to the network, the need for users to know what they are permitted to do is becoming increasingly important, not least because of the differences between licence terms.

The paper reports on the first stage of a project aiming to develop a pilot Registry of Electronic Licences (RELI) . The RELI project is funded by JISC and runs from April 2007 to March 2009. The project is a managed by Loughborough University, with partners including Rightscom, EDItEUR and Book Industry Communication (BIC), working with a small group of publishers and academic libraries. The proposed registry will enable important aspects of the licence (e.g., allowed usage conditions) to be represented to end users at the point-of-use.

The initial stage of the project involved a detailed requirements analysis process to ensure that the pilot system would meet the real needs of stakeholders. This paper presents the results of the requirements gathering process.

\section{The Challenge}

The problem of managing licence terms is exacerbated by the increasing diversity of resource providers. Some resources are available under the terms of a Creative Commons licence; others under stricter commercial terms. Although commercial systems are starting to be developed, existing library systems make it difficult for users to discover for themselves the terms that apply to any particular resource.

Reference to licence terms is labour intensive and slow. Different repertoires ${ }^{1}$ will have different licence terms for the realistically foreseeable future; as a result, technical support will be needed to facilitate compliance with licence terms without resorting to a "lowest common denominator" approach, i.e., assuming that all licences are as restrictive as the most restrictive set of licence terms.

The proposed solution lies in the establishment of mechanisms by which key elements of licences can be made available, so that a user can be provided with the most significant elements of licence information - those that relate to permitted access and use - at the point of use. In order to meet the efficiency requirements of both the user and the institution, this must be possible without routine human intervention, i.e., those significant licence terms must be machine interpretable. A licence registry, or multiple licence registries, in a (more likely) distributed model are therefore needed.

Developing a way of expressing permissions for access and use for interpretation by machines would have been a daunting proposition for the project. Fortunately this is unnecessary, because of the developing ONIX for Licensing Terms (O-LT) standard. O-LT is an XML messaging framework for the communication of licences; what was required in the RELI project was a structure for ingest, storage and dissemination of key licence terms.

\footnotetext{
${ }^{1} \mathrm{~A}$ "repertoire" is defined here as the set of resources which is covered by the terms of a particular licence.
} 


\section{A Bit of History}

In 2001, the Digital Library Federation published a report entitled 'Selection and Presentation of Commercially Available Electronic Resources: Issues and Practices' (Jewell 2001). Among other issues, this report highlighted the varying practices that US libraries use when managing licences to electronic products. This led to the formation of the Electronic Resources Management Initiative (ERMI) of the Digital Library Federation. ERMI was based on the understanding that "acquisitions and licensing processes are complex, publishers transmit this information to libraries in a variety of paper and electronic formats, and the number of licensed electronic products libraries are collecting is increasing rapidly. Such situations tend to spawn local, ad hoc fixes; what is needed, by contrast, is an industry-wide, standardized solution.” (DLF 2004).

ERMI decided that an XML-based schema for representing important elements of licences was required. ERMI focussed on two use-cases where licence data would be transferred between libraries, and proposed to develop a schema for representing this information. It considered using ERMI's own native XML schema, but also looked at two digital rights expression languages (DRELs) - MPEG 21-5 (based on XrML from ContentGuard) and the Open Digital Rights Language (ODRL). DRELs enable a description of the rights that govern the use of resources and would appear prima facie appropriate for describing licence terms and conditions.

However, DRELs are primarily designed to communicate metadata describing rights in the context of enforcement using Technical Protection Measures (TPMs) commonly called Digital Rights Management systems. TPMs tend to take the approach that everything that is not expressly permitted is forbidden, which may conflict with copyright exceptions and "fair use" (or "fair dealing”) (Chandler et al 2004).

In addition the (sometimes deliberate?) ambiguity encountered in licences is not well suited to representation in DRELs which are designed to represent an unambiguous definition of the rights associated with a resource (Coyle 2004, p. 11).

ERMI initially focussed on ODRL (preferred as an "open source” solution), developing a number of use cases and mapping these into the ODRL model. Problems with mapping to ODRL (Chandler et al 2004) however, ultimately led to ERMI developing its own native solution. ERMI explain that "placing ERMI metadata within an XML container would best be achieved without using a formal REL. Instead, using our own specific native schemas offers the best cost-benefit ratio." (Jewell et al, 2004).

In 2005, the Joint Information Systems Committee (JISC) and the Publishers' Licensing Society commissioned an investigation to determine the feasibility of developing a language for the electronic expressions of licences and the extent to which the pre-existing ERMI work might be appropriate. After a series of workshops, the requirement for such a language was established; however, it was widely agreed that, while the ERMI work provided very useful input to the process, it was inadequately expressive and flexible to form the base for a universal standard. As a 
result, work began in EDItEUR on developing ONIX for Licensing Terms (O-LT) ${ }^{2}$ (Martin 2006). O-LT was initially envisaged as a language for representing licences between publishers and libraries. However, it subsequently became apparent the other forms of licence could usefully be represented electronically, such as licences for research or teaching material deposited in a University repository.

O-LT therefore became the common framework for a set of formats, each with a different purpose but all based on a set of shared technical principles and implementation techniques - one of these formats is the 'ONIX for Publications Licence’ (ONIX-PL) format. The ONIX for Licensing Terms framework is based around an extensible ontology which defines key terms, with separate XML schemas defining the various licence formats. ONIX-PL is therefore one specific schema that forms part of the ONIX-LT family of schemata. ONIX-PL is specifically aimed at expressing licences between publishers and institutional customers (including but not limited to academic institutions). A specific licence can be expressed by a specific ONIX-PL instance that conforms to the ONIX-PL schema. Like all ONIX-LT expressions, ONIX-PL is explicitly designed for describing and communicating the terms of a licence rather than enforcing any constraints or restrictions.

In 2006 a number of workshops funded by JISC were undertaken. These aimed to extend the understanding of stakeholder requirements for the language itself, how it should be implemented, and the basic functional specification of the tools required to create (Cave 2006) and implement ONIX-PL licence expressions. The specifics of ONIX-PL were developed and a draft version of the schema was published (EDItEUR 2007). A finalised version of the schema (V1.0) is due to be published shortly). This work is currently ongoing and a number of licences for e-journals, e-books and datasets are beginning to be mapped into ONIX-PL, which therefore provides a sound technical language on which to base a licence registry.

\section{The Registry of Electronic Licences}

Based on the developments outlined above, it was decided that, in order to accurately present licence terms to end users, the RELI registry could be based on the following assumptions:

- Licence ingest format and display format: The licence ingest format will be ONIX-PL. "Out of the box" ONIX-PL may not have the necessary semantics to express all licences, and ultimately terms from other sources - Creative Commons, Creative Archive etc - will require mapping into ONIX-PL for inclusion.

- Licence and resource types: A limited range of licence and resource types can be used as exemplars within the pilot, which should cover a wide range of types of resource and, if possible, a range of commercial and non-commercial licences.

- Licence registry instantiation: The most appropriate architecture for the disposition of licence registries [centralised/federated; held by licensors/licensees/third parties] is not currently clear. The RELI project

\footnotetext{
${ }^{2}$ Onix is a metadata standard and associated vocabulary initially developed by EDItEUR and the Association of American Publishers in 1999 to facilitate the transfer of book industry metadata. It has since developed additional standards for representing serials metadata (Onix for serials). Onix for Licensing Terms is the latest development of the Onix suite of standards.
} 
should explore the advantages and disadvantages of different configurations, taking into account the needs of the JISC Information Environment. These considerations are not outlined in this paper.

Before developing the registry, the project undertook a requirements analysis exercise. Table 1 shows a list of the stakeholder groups whose representatives participated in this exercise and their stake in the process:

Table 1: RELI Stakeholders

\begin{tabular}{|l|l|}
\hline \multicolumn{1}{|c|}{ Stakeholder } & \multicolumn{1}{c|}{ Interest / stake } \\
\hline Rightsholder & $\begin{array}{l}\text { A Registry should improve clarity of understanding of users } \\
\text { in what they may or may not do with particular content. It } \\
\text { would reduce requirement for staff to answer questions and } \\
\text { assist compliance. The Registry should also help } \\
\text { rightsholders provide better user service. If desired, the } \\
\text { Registry might also make it possible for rightsholders to } \\
\text { compare their standard terms with those offered by others. }\end{array}$ \\
\hline Librarians & $\begin{array}{l}\text { Librarians are already having to deal with a wide range of } \\
\text { digital content, and many different licences and sets of } \\
\text { licence terms. This complexity will grow. The Registry } \\
\text { should provide an information resource to support } \\
\text { compliance and reduce the need for human intervention in } \\
\text { enquiries. If desired it should be possible to enable different } \\
\text { licences to be compared. }\end{array}$ \\
\hline JISC Information Environment & $\begin{array}{l}\text { The Registry should play a pivotal role in the overall } \\
\text { functionality of the JISC Information Environment. }\end{array}$ \\
\hline End-users & $\begin{array}{l}\text { Academics, teachers, students should be better able to } \\
\text { understand accurately what they can do with content they } \\
\text { have discovered. }\end{array}$ \\
\hline $\begin{array}{l}\text { JISC Content Company and } \\
\text { other Content aggregators }\end{array}$ & $\begin{array}{l}\text { Aggregators may have very different content types and rules } \\
\text { governing with their use. The Registry should make it easier } \\
\text { to manage and easier to obtain compliance. }\end{array}$ \\
\hline Subscription agents & $\begin{array}{l}\text { The key benefits for information aggregators should be } \\
\text { increased simplicity and clarity. This should reduce } \\
\text { requirement for staff to answer questions and assist } \\
\text { compliance. }\end{array}$ \\
\hline $\begin{array}{l}\text { Systems suppliers should be able to offer richer services } \\
\text { through connecting library management systems to the } \\
\text { Licence Registry. }\end{array}$ \\
\hline
\end{tabular}

This process built on the analysis undertaken by previous O-LT investigations. It took the form of two detailed and extensive focus groups held in summer 2007 and attended by all the stakeholder groups listed in Table 1 . In the focus groups a number of use-cases were discussed. Part of the process involved understanding the problems that exist in the current environment where licences are maintained in a paper-based form and the benefits that could be obtained from the implementation of the RELI registry. The remainder of this paper looks at these issues.

It should be noted that the issues presented are the views raised in the focus groups by the participants. Where these issues have informed the thinking behind the development of the RELI registry this has been indicated. However during the focus groups there were many issues that were raised which provide an insight into the general difficulties of managing licences to electronic resources; these are outlined in this paper as they provide an interesting insight into the complexities of managing the rights of electronic resources. 
One of the major difficulties that was stressed during the focus groups was that the information environment is changing rapidly and that any component of the environment (such as a licence registry) has to be flexible and able to adapt rapidly and seamlessly to change. One participant indicated: "The information environment and the culture within it changes all the time; every year there are things that need to be taken into account which weren't there before”. Within this changing environment, participants also noted that there are changing relationships between further education, higher education and commercial businesses. Participants felt that there are now more collaborations and partnerships between these bodies and, as a result, there are new issues and challenges to be addressed. This led to many areas where the focus group participants had strong views on the difficulties of managing licences and raised areas where a registry of electronic licences could help.

\section{Existing problems of licence administration 5.1 Problems with Licences}

The focus groups revealed that many of the participants felt that there were problems with the wording of licences that are currently in use. One such problem is that the licences are neither specific nor comprehensive enough. While there are JISC licences (e.g. NESLi2 ${ }^{3}$ ) that are generally very clear, there are many instances of licences from publishers that are only a single page long and omit many important terms and conditions. This frequently results in librarians having to contact publishers to clarify what they can and can't do with a given resource, a time consuming process. Often, the librarians are dealing with sales people who are not licensing experts; as a result there is sometimes a disconnect, because the publisher's sales staff say "yes" to something that is actually not permitted in the licence.

A related issue of debate among librarians was the implications if particular uses are not mentioned in the licence. ERMI seems to take the view that if something is not explicitly forbidden, then it should be seen as permitted; however this is not based on the common interpretation of copyright law (which is that if something is not explicitly listed as an exception, then by default it would be an infringement to do it), and as a result there is no consensus; we have found that many librarians are much more cautious than this.

Currently, it appears that publishers expect librarians to contact them if things are unclear. In turn, librarians expect users to contact them, and then, if they are themselves unclear, they will contact publishers on the user's behalf. It was suggested in one workshop that a mechanism for recording queries would be useful to libraries, so that an audit trail can be established, and a body of "case law" built up. The information gathered would become invaluable for informing future licence negotiation; for if libraries are aware of users' most frequent queries, then they can ensure that these issues are properly addressed in subsequent licences.

Another problem that related to the ambiguity of licences was in the definition of "authorised users". Librarians who were present among the focus group participants raised this as a big concern, as there is much confusion over who is an "authorised user” in any given case. It is important that definitions are clarified in licences as

\footnotetext{
${ }^{3}$ Nesli refers to the UK's National Electronic Site Licensing Initiative and has developed a model licence for access to electronic resources;
} 
publishers often ask that 'authorised users' are made aware of the terms and conditions of the licence; this is impossible to do if librarians don't know who the authorised users are.

Post-cancellation access is another major concern. In particular, participants reported that certain licences are not clear on the exact processes and terms on which libraries can have perpetual access to resources; librarians often have to take the step of contacting the publisher and asking them; this is usually done via an exchange of emails which must then be retained by the institution as proof of the agreement. This situation is further confused in situations where an institution has to sign one licence to use an interface, and then another licence to access specific content through that interface, e.g., when using Ovid or Swetswise. There may be problems where the two licences do not run precisely in parallel, i.e., the licence to access the data does not coincide in time with the licence to use the interface.

Focus group participants also raised the challenges that exist for those resources that are covered by terms and conditions published on the publisher's website and where no paper licence is available to refer to. Librarians find this to be problematic because, unlike paper licences, they get no notification of changes made to terms and conditions of use unless they constantly go online and check for themselves.

A common issue is the increasing use of repositories and virtual learning environments (VLEs) in institutions. However licences rarely reflect this type of use specifically and often do not explain, for example, whether extracts can be taken from a resource and included in a repository, or whether it is only allowable to link to the resource (as in case of $\mathrm{JSTOR}^{4}$ licence)

Although a licence registry will not in itself solve all these problems, it is hoped that the coding of licences into ONIX-PL (a requirement for the ingest of licences into the registry) will enable some of these issues to be more clearly flagged up. For instance, the process of converting a licence into ONIX-PL will ensure that the groups that constitute authorised users will have been properly considered; this may remove this kind of ambiguity from licences.

\subsection{Interpreting Licences}

The focus groups revealed that not only do librarians have problems with licences themselves, but they also often experience difficulty when interpreting licences. The general consensus was that interpreting a clause within a licence and presenting it in a meaningful way involves risk, because there is a danger of misinterpreting the legal terms. This could lead to wrong information being passed onto users. To prevent this from happening, most librarians tend to err on the side of caution, as a result of which some resources might not be made available to users, or under unnecessarily restrictive conditions. Clearly a licence registry should help in this regard.

\subsection{Multiple Licences and Repertoire Management}

Many institutions have lots of resources that are accessible through a number of differing channels (e.g. publisher, aggregator, etc.), and each has a different licence, resulting in overlapping licences for the same resource and conflicting terms for the

\footnotetext{
${ }^{4}$ JSTOR is a trusted digital archive for scholarly articles and resources.
} 
same user. In practice, these overlapping licences do not cause librarians major problems. Some institutions use context sensitive link servers (such as Ex-Libris' SFX) to enable librarians to identify where the resource is being accessed and therefore identify which licence is associated with the resource. However, it is clear that a Licence Registry will need to be able to take multiple licences into consideration. The issue of what happens when one licence gives permission to do something but another doesn't was raised. Although the precise functionality of the licence registry has yet to be determined, a suggestion was raised by one focus group participant that the text presented to the user could point them to a similar or identical resource under which they are permitted to do things. This would help make the best use of resources. The publishers who were present in the focus groups didn't see any problem with this, but suggested that more commercially orientated publishers might take a different view.

The situation is further confused by the fact that individual articles can be covered by different terms within the same Journal. For example, some journals have some articles that are Open Access and some covered by a licence (e.g., Springer's Open Choice). The licence registry would have to be able to recognise the differences. In the same way, some articles are the result of research funded by Governments, and should be made available under different terms i.e., copyright was not assigned to the publisher. In addition, as authors become more aware of Open Access, they are increasingly demanding to retain copyright in their submitted articles. The publisher agrees to this when the article is accepted for publication. However, this is often overlooked in the licensing.

Increasingly, publishers are now also providing “click through” licences to address the end-user directly rather than relying on the libraries providing the licence information to users. These click-through licences enable publishers to communicate usage terms to end-users, effectively disintermediating the library in this respect. When these licences are used by publishers, the user usually has to tick a check box before gaining access to a resource. However, librarians commented that the terms and conditions specified in such 'click through licence' are, in some instances, more restrictive than the licence signed with the institution. This raises the question: which licence takes precedence? The general feeling seemed to be that the institutional licence should apply in the case of such conflicts.

Even when the appropriate licence has been established, there are still complications that need to be addressed. The most frequent complication is that licences often classify users into specific groups, and provide differing terms and conditions for each class of user. User identity, and particularly the identification of a user as belonging to a specific class, is therefore a crucial element in licence administration. A potential solution to accurate determination of the status of users (alumni, corporate users, partnership colleges, etc.) may be to use Shibboleth. Shibboleth provides the necessary functionality and granularity of roles to differentiate between categories of users. However, in practice this functionality of Shibboleth is not widely implemented as yet. As part of the development of the pilot licence registry, the suitability of Shibboleth is being investigated. 


\section{User Perceptions of Licensing Issues}

The focus groups also revealed a range of user perceptions and issues that reinforce the need for a Licence Registry. Librarians suspect that, at the moment, end users do not consider the terms and conditions covered in the licences governing access to resources. Users rarely consider asking library staff to clarify the terms of a licence and this sometimes results in breaches of licence terms through ignorance. Placing licence terms at the point of use would address the issue of ignorance.

Librarians in the focus groups commented that under-use of resources does not appear to be a problem, and that both students and academics generally use the resource without being deterred by worries about licence terms. It was made clear in the focus groups that end user expectations are changing: they expect material to be easily accessible -- and they expect it to be free for any use. Issues such as sharing Athens passwords on social networking sites are not uncommon and show that end-users are both breaching acceptable use policies and ignoring licensing issues. Whilst the Licence Registry may not be able to change user expectations and actions, it will provide users with the licence terms and therefore will help them make informed decisions.

However, a licence registry that presents licence terms to users will not be a panacea; users are often unsure of the use that they will make of licensed materials and the usage may change. For example, a user may initially access a resource solely for the purpose of including part of the resource in a presentation at conference. However, it is possible that the presentation may then be placed on a conference website or published in conference proceedings (which may then be sold for commercial purposes). A licence registry will not police the usage of a resource and if an author accesses material for one purpose, it should be remembered that it may end up being used for another. This could result in the licence terms being breached unintentionally. However, it is expected that the licence registry's aim of presenting licence terms to users at the point of use will lead to a general raising in awareness of the issue of licensing terms which may, in turn, eventually lead to a reduction in unintentional breaches.

\section{Issues directly related to the Licence Registry}

This section discusses the issues raised by focus group participants that would directly affect the development of a Licence Registry.

\subsection{What materials should the Licence Registry cover?}

In a constantly changing information environment, anything that is put on the Internet can be licensed. Focus group participants felt that in order to be useful, the Licence Registry needed to reflect this and should aim to cover e-journals, databases, images (e.g., ArtStore, JISC Image Database), moving images and audio (e.g., Archival sound recording - a free resource but users still need to sign a licence). A suggestion was made that e-book licences should be incorporated into the registry, as in the future, their uptake may have grown immensely. There is a lot of variety amongst what publishers offer under the terms and conditions of each e-book licence; some offer site licences, whilst others offer single use or concurrent use. The Licence Registry will need to take these variations into consideration.

\subsection{The scope of a Licence Registry}


There were many questions posed in the focus groups regarding the scope of the Licence Registry. These are highlighted below and will be taken into consideration in the design stage of the project.

Focus group participants were asked which licences they felt should be included in the Licence Registry. They suggested that even if the registry was restricted to NESLi and CHEST licences ${ }^{5}$, it would still be very helpful as it would cover a large number of journals. However participants went on to say that although the proposed registry has a UK focus, licences with overseas publishers exist and will need to be accounted for in the Licence Registry. Similarly, aggregators will have agreements with international publishers, the terms of which must be passed on to the libraries/end users.

Another question that needs to be considered in the design stage is whether the registry will cover institutional repositories, virtual learning environments and the licensing of theses, etc? In these cases the copyright may belong to the institution or student. With the submission of theses into repositories increasingly being made compulsory by institutions, it seems sensible to include such licences in the Licence Registry. In some of these cases (such as VLEs or institutional repositories) institutions may not currently have usage licences for their repositories. However, if they do, then the focus group participants indicated that the Licence Registry needs to take this into account.

\subsection{How electronic licences are created and maintained}

Focus group participants were asked to consider how they would expect electronic licences to be created and maintained by the Licence Registry. Licence creation and ingest is an important aspect of the Licence Registry. In order to ensure that the electronic version of a licence represents the publisher's interpretation of the physical licence, and to ensure that electronic expressions of licences are available for ingest into the Licence Registry, librarians suggested that publishers should make electronic version of licences available; then at an institutional level they can be interpreted employing user friendly, simple text. The publishers in the focus groups indicated that they would be prepared to create machine-readable licences if there was a demand.

There was also discussion about how the licence terms would be presented to the user, i.e. would it be the exact clauses from the licence or an interpreted user friendly version of the licence? The conclusion was that if publishers want a direct relationship with a user, i.e. a 'tick' to accept terms and conditions, then the registry should not provide a user friendly interpretation; it should present the publisher's text. However, it is expected that the registry be mostly used for informational purposes; in this case a user friendly interpretation of the licence is appropriate. An issue to note, and something that the Licence Registry will have to have a mechanism in place to deal with, is that licences, particularly those from aggregators, change. If a new publisher is added to the aggregation, then the licence terms may need to be altered. This needs to be indicated to the library and subsequently to the end users.

CHEST agreements are maintained by EDUServe and cover software and information licence agreements in Universities and Colleges. 
In the focus groups, librarians indicated that the ability to compare publisher licences at negotiation time with standard institutional policies regarding licences would be desirable. This is something that currently would be out of the scope of the Licence Registry but could be considered in the future.

\subsection{Dissemination of Licence Terms}

Focus group participants agreed that making licence terms clearly available to users is very important. Institutions may be held vicariously liable if employees or students breach licence terms and the institution has not taken sufficient steps to make the terms available to end users. However, they also pointed out that only those aspects of the licence that directly affect the user need to be shown, for example, usage permissions and restrictions. They felt that it would be most appropriate to present the licence terms to users at point of use, and suggested that this could even occur at the article level.

A general feeling was that using the software to ensure enforcement of the licence terms is not required. However, reports of when/how usage terms were queried would be useful for future licence negotiation.

\subsection{What needs to be displayed to the user?}

Participants in the focus groups were asked what they expected to be displayed to the end user. General consensus was that the user interface is important and that it must not scare users. Participants agreed that simple, concise text expressing the basic usage terms of a licence with legal speak omitted would be most appropriate. It was clear from the participants that it is important to provide information about what IS permitted as much as what IS NOT permitted.

Participants suggested that a traffic light system would be appropriate, so that it is obvious to users what is acceptable and what isn't. In such a system, a red light would indicate to users what definitely is not allowed, an amber light would indicate that the user needs to seek guidance from a member of staff and a green light would indicate what is permitted. Symbolic representation was another suggestion made in the focus groups. For example, red crosses could be used to highlight what is not allowed and green ticks could be used to show what is permitted. This kind of symbolic representation would be user friendly and make permissions and restrictions obvious to users.

There was some discussion of context-dependent presentation of terms. For example, would it be possible to inform users of restrictions governing, say, print, only when they actually go to print a document? Given the early stage of development of the Licence Registry, this is not something that will be implemented, but it could be considered in the future.

A suggestion was made that there could be a link to the publishers' permissions department if human intervention is needed. Both librarians and publishers agreed that if the legitimacy of a proposed action is ambiguous, then queries should go directly to the publisher. However, if the proposed action could lead to additional fees e.g., if an academic wanted to print out more copies, then the librarian should be contacted first because an element of budget management would be involved. 


\subsection{Integration Issues}

Library systems providers are currently also looking into developing modules for presenting licence terms, and the relationship between these systems and the Licence Registry proposed in this paper needs to be considered. One solution may be that function and data could be shared. For instance a central licence repository could communicate with an electronic resource management (ERM) system which could download licence data from it (indications are that ONIX-PL would be an appropriate form for this transfer). The presentation to end users would therefore be the responsibility of the ERM system.. However, for the foreseeable future, there will be mixed-mode operations, with some institutions having ERM systems and some not. Libraries represented in the focus groups without ERM systems liked the proposed functionality of the Licence Registry. There was discussion that the registry could provide some of the functionality of an ERM system, e.g., providing reminders of renewal dates. However, although this would be a possibility, it is outside the scope of the pilot registry

\subsection{Functionality of the registry}

When considering the functionality that should be built into the registry, the possibility of being able to search on usage definitions in licences was considered, e.g., "show the resources we subscribe to that can be mounted on a VLE" (perhaps for use as a case study by a lecturer) . However, concerns were raised that this complexity would have a negative impact on the usability of the registry and it was decided that this should not be a feature of the pilot Licence Registry.

\section{Conclusions}

There are many issues surrounding the management of licences to electronic material. Librarians feel that licences are often not specific enough, which result in them having to contact publishers and seek clarification. A lot of confusion exists over who are "authorised users" in the context of any particular licence. Perpetual access is another area that is often overlooked in licences; again, librarians have to contact publishers for clarification. Librarians find this to be a time-consuming process which involves them in having to maintain the exchange of emails with publishers as proof of the eventual agreement.

Librarians find that interpreting licences presents many problems. If the meaning of clauses is obscure, most librarians tend to err on the side of caution and do not allow users to make any use of a resource if they are not completely clear about its legitimacy. Another problem with interpreting licences is that it can be difficult to present the clauses within the licence in a meaningful way without expert unpicking of the "legal jargon".

Multi-level licences where interfaces are provided under one licence and content under another cause concerns as the licences don't always coincide with one another. Overlapping licences also cause problems, as the same resource may be licensed under two or more separate licences with different sets of terms for the same user.

A Licence Registry implemented using ONIX-PL alongside standard definitions of usage terms should help to resolve many of these issues. 
With regards to the Licence Registry, all participants agreed that making licence terms available to users is important and therefore there is a requirement for such a registry and that it would be useful. They suggested that some kind of symbolic representations should be displayed to users to show them clearly what is permitted and what is forbidden, and agreed that only key usage terms need to be displayed to users. Librarians also want publishers to make electronic versions of licences available at an institutional level so they can be interpreted and the interpretation attached to resources. Librarians indicated that integrating the licence registry with existing library management systems would be desirable.

Publishers would like to be able to offer one broad general licence, but it is not possible due to differing conditions on the sale of journals. Publishers will be willing to create machine-readable licences when it can be shown that there is a demand for them.

Given these findings, it is clear that there are real stakeholder requirements for a licence registry. The next stage of the RELI project will use the information gathered from the focus groups to develop a technical architecture for the Licence Registry.

Subsequently a pilot registry will be developed and tested by selected users towards the end of 2008.

\section{References}

Cave F., 2006. Tools to help publishers and libraries produce OLT licences.

Presentation to BIC seminar July 2006. Available at www.bic.org.uk/ppt/060705francis_OLT.ppt [accessed 15/06/2007]

Chandler, A., Farb, S., Riggio, A., Robertson, N., Silterra R., St. Laurent, S. and Wendler R., 2004 XML Investigation. Available at

http://www.diglib.org/pubs/dlf102/d

lfermi0408appf.pdf [accessed 14/06/2007]

Coyle K. "Rights Expression Languages: A Report for the Library of Congress." February, 2004. Available at:

http://www.loc.gov/standards/Coylereport_final1single.pdf. [accessed 14/6/07]

DLF 2004 DLF Electronic Resources Management Initiative. Available at http://www.diglib.org/standards/dlf-erm02.htm. [accessed 14/06/07]

EditEur, 2007. ONIX for Licensing Terms Publications License message format.Available at http://www.editeur.org/licensing/070302_ONIXPL_\%20format_0.9.26.pdf [accessed 21/04/2008]

Jewell T, 2001. Selection and Presentation of Commercially Available Electronic Resources: Issues and Practices, Digital Library Federation and the Council on Library and Information Resources. Available at http://www.clir.org/pubs/reports/pub99/contents.html [accessed 14/06/07] 
Jewell T, Anderson I, Chandler A, Farb S, Parker K, Riggio A, Robertson N, 2004. Electronic Resource Management Report of the DLF ERM Initiative. Digital Library Federation. Available at http://www.diglib.org/pubs/dlf102/dlf102.htm [accessed 3/8/08]

JISC 2006. JISC Circular 04/06 Capital programme. Available at http://www.jisc.ac.uk/fundingopportunities/funding_calls/2006/09/funding_circular04 _06.aspx [accessed 14/06/07]

Martin D., 2006. Presentation at Onix-PL Implementation workshop in Boston. Available at www.niso.org/committees/License_Expression/Martin_ONIXPL_Boston.pdf [accessed 14/06/07]

RELI, 2007. Available at http://www.lboro.ac.uk/departments/dis/disresearch/RELI/ [accessed 14/06/2007] 